\section{Giardiosis tendencias terapéuticas en niños y adultos}

Giardiosis therapeutic trends in children and adults

Lisbeth Katherine Cevallos Hernández

Médico general. Hospital General del

Norte de Guayaquil Los Ceibos

drakalisce8@hotmail.com,

https://orcid.org/0000-0001-5121-6360,

Guayaquil, Ecuador

Gabriela Elizabeth Shuguli Rivera

Médico general. Centro de Salud de

Poaló Cotopaxi, Latacunga , estefany-

carolprinces@hotmail.com,

https://orcid.org/0000-0002-8272-3434,

Guayaquil, Ecuador

Karla Alejandra Jaramillo Vinueza

Médico general. Consultorio Médico

Monserrat,

karla.jaramillovinueza@hotmail.com,

https://orcid.org/0000-0002-9601-7362

Guayaquil, Ecuador

Tania Lisset Saavedra Carchi

Médico general. Consultorio Médico

particular, tania.s88@hotmail.com,

https://orcid.org/0000-0003-1505-8187,

Guayaquil, Ecuador

http://www.jah-journal.com/index.php/jah

Journal of American health

Julio - Diciembre vol. 3. Num. 2 - 2020

Esta obra está bajo una Licencia Creative

Commons

Atribución-NoComercial-CompartirIgual

4.0 Internacional.

RECIBIDO:9 DE MARZO 2019

ACEPTADO: 9 DE NOVIEMBRE 2019

PUBLICADO: 2 DE JULIO 2020

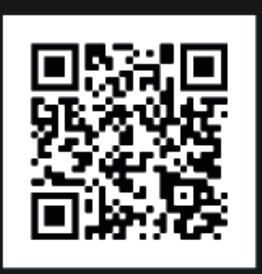

Scan this QR

code with your

smart phone or

mobile device to

read more papers

\section{RESUMEN}

Es una enfermedad cosmopolita causada por el protozoo Giardia lamblia a través de ingestión feco-oral luego reside en el intestino delgado superior donde destruye el enterocito y las velocidades, afecta a poblaciones con bajos recursos económicos donde las condiciones higiénico sanitarias y educativas son deficientes, constituye una enteritis de gran importancia epidemiológica y clínica por su alta prevalencia y patogenicidad, está relacionado a niños en edad preescolar y adultos inmunodeprimidos, es causa de diarrea aguda acuosa, desnutrición crónica y puede producir colon irritable y cuadros alérgicos. Presentamos una actualización sobre los aspectos terapéuticos de la giardiasis mediante revisión documental, detalla los diversos fármacos terapéuticos útiles en niños y adultos, disponibles en contexto de 9 casos clínicos publicados para alcanzar el objetivo de esta investigación. El tratamiento consiste en medidas de soporte para la diarrea y antiparasitarios tales como el metronidazol, tinidazol, nitazoxanida, albendazol que son bien tolerados por los pacientes pediátricos. Es controversial el tratamiento preventivo con fármacos, sin embargo los casos asintomáticos se recomienda realizar esta, bajo ciertos criterios como el estado de inmunodepresión del paciente $\mathrm{o}$ de acuerdo al riesgo de transmisión de la infección, los casos de recaída por esta entidad requieren repetir la terapia, incluidos dos fármacos para cubrir la resistencia, lo que puede ayudar a garantizar la seguridad de curación considerando que los fracasos terapéuticos son cada vez más comunes.

PALABRAS CLAVE: albendazol, metronidazol, tinidazol, Giardia, lamblia, terapia, giardiosis 


\section{ABSTRACT}

It is a cosmopolitan disease caused by the protozoan Giardia lamblia through fecooral ingestion, then it resides in the upper small intestine where it destroys the enterocyte and velocities, it affects populations with low economic resources where hygienic, sanitary and educational conditions are deficient, constitutes An enteritis of great epidemiological and clinical importance due to its high prevalence and pathogenicity, it is related to preschool children and immunosuppressed adults, it is the cause of acute aqueous diarrhea, chronic malnutrition and can produce irritable colon and allergic symptoms. We present an update on the therapeutic aspects of giardiasis through a documentary review, detailing the various useful therapeutic drugs in children and adults, available in the context of 9 published clinical cases to achieve the objective of this research.
Treatment consists of supportive measures for diarrhea and antiparasitics such as metronidazole, tinidazole, nitazoxanide, albendazole that are well tolerated by pediatric patients. Preventive drug treatment is controversial, however asymptomatic cases it is recommended to perform this, under certain criteria such as the patient's immunosuppressed state or according to the risk of transmission of the infection, cases of relapse by this entity require repeated therapy, including two drugs to cover resistance, which can help guarantee the safety of cure considering that therapeutic failures are increasingly common.

KEYWORDS: Albendazole, Metronidazole, Tinidazole, Giardia, Lamblia, Therapy, Giardiasis

\section{INTRODUCCIÓN}

La giardiasis es una de las infecciones diarreicas parasitarias más comunes que afectan a los humanos (1), causada por el parásito protozoario G. lamblia, se transmite por la ruta fecaloral, frecuentemente a través de la ingestión de agua y alimentos contaminados o la transmisión de persona a persona (2), y parece ser un factor de riesgo significativo para el síndrome de fatiga crónica y el intestino irritable postinfeccioso (3).

Este protozoo puede infectar a cualquier persona, distribuida mundialmente es causante de cuadros clínicos diversos que van desde diarreas disenteriformes con dolor abdominal recurrente, duodenitis e yeyunitis, tiene una mayor incidencia en niños causando problemas en el crecimiento y desarrollo normal, lo que se pondrá de manifiesto en su desempeño escolar (4).

Es causa frecuente de enfermedad diarreica aguda en menores de cinco años y de dolor abdominal recurrente en el niño mayor (5), los niños pequeños y las embarazadas son más susceptibles a la deshidratación provocada por la diarrea, así que se debe tomar más precauciones para asegurarte de que estas personas beban muchos líquidos (6), Es una enfermedad común en entornos de bajos recursos, a menudo se presenta con flatulencia y diarrea acuosa. En los Estados Unidos, la enfermedad se ve con mayor frecuencia en viajeros internacionales, viajeros de la naturaleza y trabajadores de guarderías (7). 
Giardiasis y la criptosporidiosis son reconocidas por la OMS como enfermedades emergentes importantes del siglo XXI. Los síntomas son similares e incluyen diarrea y vómitos, que pueden ser graves, incluso potencialmente mortales, para los inmunocomprometidos y los niños menores de cinco años. Entre 2013 y 2017, el Instituto de Salud Pública de Serbia registró 10 epidemias transmitidas por el agua que se manifestaron como enfermedades gastrointestinales. (8)

Sin embargo puede aparecer en adulto con condiciones de riesgo, como las inadecuadas medidas de prevención utilizadas por la familia (9), o en pacientes con inmunodepresión por cualquier causa, con que el personal de enfermería encargado de esta población debe realizar las actividades de prevención y promoción de salud

El tratamiento es en bases ametronidazol, albendazol, sin embargo también se han realizado estudios con otras sustancias como el Oleozón ${ }^{\circledR}$ lo que resultó efectivo en el tratamiento contra la giardiasis, pues las muestras de heces fecales dieron negativo en todos los casos; además, sin producir reacciones adversas y su costo es bajo, lo que conlleva un impacto económico, social y medioambiental (10).

Otros trabajo hablan de la terapia con propolina donde resultó útil en pacientes diagnosticados con giardiasis que no respondieron a tratamientos medicamentosos habituales. (11)

El oleozon ${ }^{[R]}$ es un medicamento desarrollado en el Centro de Investigaciones del Ozono del Centro Nacional de Investigaciones Científicas, a partir de la ozonización del aceite de girasol en condiciones adecuadas (12)

Por tal motivo presentamos una actualización sobre los aspectos terapéuticos de la giardiasis mediante revisión documental, detalla los diversos fármacos terapéuticos útiles en niños y adultos, disponibles en contexto de 9 casos clínicos publicados para alcanzar el objetivo de esta investigación.

Estudio descriptivo, documental cuyos datos fueron recolectados a través de fuentes secundarios en revistas indexadas, libros, sitios web publicados en los últimos cinco años 2015 al 2020 salvo los de relevancia científica de años previos (no más de diez años), utilizando las palabras claves "albendazol", "metronidazol", "tinidazol", "giardia" "liamblia", "terapia". Se escogió entre los idiomas el inglés y español se descartaron otros; seleccionado 28 artículos de los cuales 9 fueron imprescindibles y relevante para alcanzar el objetivo de esta investigación, donde detalla los diversos esquemas terapéuticos en niños y adultos usados en esta morbilidad presentados a manera de casos clínicos. Los criterios de inclusión fueron artículos de revisión documental cuyo tema central fue la giardiasis enfoque terapéutico.

\section{PRESENTACIÓN DEL CASO}

\section{Caso \# 1}

Herrero Aguirre, 2018 observo en su investigación con 116 pacientes mayor frecuencia en edades de 1 a 18 años, presentaron dolor abdominal, vómito y anorexia se cree que el factor de riesgo es que asistieron a guardería infantil, con una "predisposición" a contraer esta parasitosis y en los que se encontró una mayor asociación con la diarrea como síntoma clínico; sin embargo, no se conocen bien los factores, tanto del parásito, del huésped o del medio, que están involucrados en la génesis de este fenómeno, el método diagnostico se realizó a través de coproparásitario. En la serie se obtuvo que el mayor número de los pacientes del grupo experimental, cuyo esquema terapéutico incluía el Oleozón, resolvió el dolor abdominal y 
mejoró su estado general al disminuir el resto de los síntomas con control posterior de las muestras de heces fecales sien negativas en todos los casos; además, no se produjeron reacciones adversas y su costo es bajo, lo que conlleva un disminuir el impacto económico, social y medioambiental. (13)

\section{Caso \# 2}

Por otro lado Martínez Gordillo, 2014 detalla un caso de paciente con dolor abdominal crónico, diarrea o fiebre pastosa, sin fiebre. Se realizó estudios de heces que fueron negativos para patógenos y el test de aliento de hidrógeno de lactosa fue positivo. El diagnóstico clínico presuntivo fue giardiasis luego se repiten las pruebas con resultados positivos y fue tratado en primer tratamiento con nitazoxanida. Sin embargo, el paciente persistió con dolor abdominal y heces pastosas, agregando tinidazol, con evolución favorable las pruebas posteriores mostraron que la absorción de lactosa era normal, los exámenes de heces eran negativos para Giardia y el dolor abdominal se había detenido. (14).

\section{Caso \# 3:}

Iza José A., 2019 presento a un hombre de 39 años con manifestaciones clínicas de infección por Giardia que no respondía a tratamientos estándares entre la manifestación clínica presento diarrea (tres deposiciones sueltas al día); dolor abdominal difuso de intensidad moderada, hinchazón, náuseas, distensión abdominal, eructos, pérdida de peso, astenia y adinamia con diagnóstico de giardiasis el que fue confirmado por la detección de quistes de G. lamblia y trofozoítos en frotis fecales, luego el paciente fue reevaluado debido a la persistencia de los síntomas y giardiasis donde observaron la persistencia de quistes de lamblia y trofozoítos en muestras fecales .Los paciente y su familia negaron haber conocido riesgo factores para la giardiasis, y el historial médico del paciente no sugirió la presencia de inmunodeficiencia iniciando con metronidazol de 500mg por 7-dias luego recibió un 4 semanas curso de metronidazol oral, $750 \mathrm{mg}$ administrados b.i.d., seguido de $500 \mathrm{mg}$ de metronidazol administrado b.i.d. durante 2 semanas, lo que resulta en una mejora parcial de los síntomas. (15).

\section{Caso \# 4}

González Gámez, 2015 realizó una intervención terapéutica en 108 adultos con giardiasis, atendidos en el Servicio de Medicina Natural y Tradicional del Centro Médico Psicopedagógico "América Labadí Arce" de Santiago de Cuba, desde julio del 2013 hasta igual periodo del 2014, con vistas a determinar la efectividad del Oleozon ${ }^{\circledR}$ oral en los afectados. Aproximadamente $50 \%$ de los pacientes sintomáticos tienen complicaciones, tales como diarreas crónicas, urticarias, desnutrición y/o bajo peso y malabsorción intestinal. Antes y después de cada ciclo de tratamiento, se les realizaron a todos los afectados, los exámenes complementarios siguientes: hemograma completo, hierro sérico y heces fecales seriados. La rápida evolución de los pacientes tratados con Oleozon ${ }^{\circledR}$ demostró su efectividad; por tanto, se recomendó su utilización como enfoque terapéutico de elección. (16)

\section{Caso \# 5}

Se practicó el examen de selección a unos 300 niños y se seleccionaron los positivos para Giardia lamblia, realizado por Telmo E. Fernández Ronquillo, donde resulto 62 niños, con edad mínima 3 años y edad máxima 13 años. El total por sexo: 28 varones y 34 mujeres. La evaluación total se hizo en 59 niños, mientras que tres de ellos no acudieron a los controles y no se pudo cuantificar el resultado. Estos son excluidos. Ninguno de los 62 infantes presentó 
signos o síntomas de algún proceso patológico o enfermedad concomitante. Examen directo y por concentración de las heces y control y para el tratamiento se indicó albendazol, $400 \mathrm{mg}$ diarios, en una dosis diaria, vía oral administrada por 5 días consecutivos. De los 59 niños que terminaron la evaluación $56(94,9 \%)$ fueron declarados curados, pues hasta el segundo examen de control (día 22) no presentaron quistes de G. lamblia en sus heces. (17)

\section{Caso \# 6}

Robalino, Lasso Yuliana detalla un paciente masculino, de 26 años, acude a consulta a un centro de salud por presentar los siguientes antecedentes: Carga genética para diabetes mellitus e hipertensión arterial, Padecimiento evolutivo de evacuaciones sanguinolentas, dolor abdominal tipo cólico, Disminución de peso acompañados de síntomas de gastroenteritis desde hace 3 meses, que han sido manejados con ciprofloxacina $500 \mathrm{mg}$ cada 12 horas, trimebutina $200 \mathrm{mg}$ cada 8 horas. Refiere consumo de alcohol semanal. El examen confirmatorio se efectuó por un análisis coproparasitológico, donde se encontró quistes de Giardia lamblia en cantidades fuera de lo común mediante un riguroso análisis microscópico de las muestras presentadas durante los tres días. Se hace énfasis en que se realicen las medidas de prevención e higiene para disminuir la probabilidad de aumentar casos de parasitosis por Giardia lamblia es tratado con metronidazol y tinidazol (18).

\section{Caso \# 7}

Además Elizalde, 2002 publico un estudio de casos de 57 casos con diagnóstico de G. lamblia singularmente, presentaron diarrea, anorexia, epigastralgia, náuseas y baja ponderal.En el material fecal de ellos se realizó: 1) Reacción de Thevenon en heces; 2) Coloración de azul de metileno y lugol; 3) Concentración del parásito con la técnica de centrífugo - flotación de Faust; además 4) Hemograma; 5) Enterotest, 6) Estudio radiológico contrastado y la sintomatología cedió al manejo médico con metronidazol (26 giardiásicos) y/o albendazol (31 giardiásicos) (19).

\section{Caso \# 8}

La Dra. Álvarez, en el 2014 realizó una intervención terapéutica en 76 pacientes con giardiasis, impétigo contagioso y epidermofitosis de los pies, la mayor afectación de epidermofitosis de los pies en los varones pudo estar dada por la práctica de actividad física que es superior en los mismos, y por tanto, aumenta la sudoración. Además, el uso de calzados cerrados durante varias horas del día es un factor importante en la patogenia de la enfermedad. Se trató con Oleaozon. Obteniendo resultados favorables en $78,9 \%$ de los pacientes, entre los cuales sobresalieron los que tenían giardiasis e impétigo (20).

\section{Caso \# 9}

Redondo Granado en el 2009, presentó el caso de un varón de 12 años, español aquejado de dolor cólico abdominal y flatulencia de un mes de evolución, acompañado de diarrea intermitente que interfiere en la asistencia al colegio, tanto por el dolor como por la urgencia defecatoria. Se enviaron tres muestras de heces para la búsqueda de parásitos al laboratorio de un hospital de la ciudad con resultado negativo. Un mes después, y ante la persistencia de los síntomas, así como por la pérdida de peso de aproximadamente $4 \mathrm{~kg}$, se analizaron otras tres muestras en el laboratorio de otro hospital, hallándose, en este caso, quistes de Giardia lamblia. Se realizó tratamiento con metronidazol a dosis de $500 \mathrm{mg}$ cada 8 horas durante una semana, mejorando discretamente el dolor abdominal y la diarrea pero persistiendo tras la ingesta de leche. Se retiró la lactosa de la dieta y se intentó la introducción al mes sin éxito, por 
lo que se retiró otro mes más. Se prescribió otro ciclo de tratamiento con metronidazol a las mismas dosis. A partir de este momento desaparece la sintomatología digestiva y se produce una recuperación del peso. Los estudios coproparasitarios posteriores han sido negativos (21).

\section{CONCLUSIONES}

Según las referencias científicas el metronidazol administrado durante 5 a 7 días produce tasas de curación del 80 al 95\% de forma similar el tinidazol incluso se han registrado resultados con mayor eficacia con beneficios sobre tratamiento más corto. Por otro lado la nitazoxanida es tan eficaz que el metronidazol y el tinidazol utilizado por oral en un curso de 3 días se puede utilizar hasta un año, y el albendazol, el mebendazol y la paromomicina son bien tolerados por los niños. En el caso de Oleaozon obtuvo buenos resultados. Sin embargo y a pesar de la disponibilidad de estos fármacos también se han reportado las recaída por Giardia lamblia, por lo que se recomienda repetir la terapia en pacientes inmunocompetentes, incluidos dos fármacos para cubrir la resistencia, y en pacientes inmunocomprometidos tratamientos más prolongados así como recomendaciones sobre ingestión de lácteos y el tratamiento a los portadores asintomáticos solo de recomienda bajo ciertos criterios de acuerdo al estado de inmunodepresion.

\section{REFERENCIAS}

1. Córdova M. Mayaro and Chikungunya; two alphaviruses with clinical and epidemiological similarities. Scielo. 2016.

2. Salud GGdle. Virus Mayaro. Hoja informativa. Centro Provincial Información de ciencias médicas, Centro Provincial Información de ciencias médicas; 2016.

3. Navarro JC. Dos nuevos registros de vectores potenciales de Fiebre Amarilla selvática y Mayaro para el Ecuador. Scielo. .

4. Salud OPD. Alerta epidemiológica por Mayaro. OPS. 2019 mayo.

5. Zúñiga IR. Virus Mayaro: Nueva amenaza para el continente Americano. Revista Latinoamericana de infectología. 2017 marzo; 30(1).

6. Muñoz M. Virus Mayaro: Reemergente en Venezuela y Latinoamérica. Revista de Tema. 2014 Abril.

7. Rubio Y. Primer reporte de Aedes (Stegomyia) albopictus (Skuse) (Diptera: Culicidae) en el estado Bolívar e implicaciones epidemiológicas. Scielo. 2016.

8. Arévalo-Cepeda YP. Virus mayaro: un arbovirus que amenaza a Colombia. Revista de Medicina e Investigación Universidad Autonoma de Mexico. 2018 Julio.

9. García A. Arbovirus en Latinoamérica. Scielo. 2017.

10. Salud OPdl. Instrumento para el diagnóstico y la atención a pacientes con sospecha de arbovirosis. Biblioteca Sede de la OPS. 2016 Junio.

11. Halsey ES. Mayaro Virus Infection, Amazon Basin Región, Perú, 2010-2013. Emerging infectious Diseases. 2013 Noviembre.

12. Carod-Artal FJ. Complicaciones neurológicas asociadas a la infección por el virus del dengue. Revista de Neurología. 2019 Mayo.

13. Elbendary AM. Dermatologic Manifestations of Viral Hemorrhagic Fevers Treatment \& Management. Medscape. 2019 Enero. 
14. Bernal-Vera CM. Estandarización de una técnica de RT-PCR anidada para detección de alfavirus. Scielo. 2017 Agosto.

15. Salud OPdl. Actualización epidemiológica del dengue. OPS. 2019 junio.

16. MI. F. Emerging alphaviruses in the Américas: Chikungunya and Mayaro. Scielo. 2014 Diciembre.

17. Donaires CCyF. Enfoque sindrómico para el diagnóstico Y MANEJO. Revista Médica de Perú. 2017 Septiembre.

18. CR. A. Mayaro virus: a new human disease agent. II. Isolation from blood of patients in Trinidad, B.W.I. The American Journal of tropical medicine. 2014.

19. RogelioLópez-Vélez CRy. Alfavirus tropicales artritogénicos. Reumatología clínica. 2018 Julio.

20. C H. Peptide motif analysis predicts alphaviruses as triggers for rheumatoid arthritis. Elsevier. 2015 octubre. 